\title{
Effects of turbulence on the development of phytoplankton biomass and copepod populations in marine microcosms
}

\author{
Miguel Alcaraz, Enric Saiz, Celia Marrasé, Dolors Vaqué
}

Institut de Ciències del Mar, $\mathrm{P}^{\circ}$ Nacional S/N, 08003 Barcelona, Spain

\begin{abstract}
Effects of turbulence on the dynamics of copepods as well as on the development of phytoplankton biomass were studied in $30 \mathrm{dm}^{3}$ laboratory microcosms. Two experiments were carried out, with different successional stages of the plankton populations, using seawater from the Masnou nautical harbour, $20 \mathrm{~km}$ north of Barcelona. Two experimental conditions were established (stirred microcosms with copepods, and unstirred microcosms with copepods). Enclosure of plankton populations was followed by a phytoplankton bloom, which differed in intensity in stirred and unstirred microcosms. Time changes in the abundance of the different developmental stages of copepods (from eggs to adults), sex ratios $(\delta / q+\delta)$, fecundity (no. eggs/no. females), total copepod biomass, and the ratio consumers/producers, also differed in stirred and unstirred microcosms. Turbulence seems to reduce consumer biomass through changes in the demographic composition (lower proportion of males and higher development rates) and probably by increasing the metabolic activity of copepods (feeding pressure and excretion rates). The ultimate effect of turbulence would be a reduction of the trophic efficiency of the system, and accelerated turnover rates.
\end{abstract}

\section{INTRODUCTION}

Turbulence and herbivorous zooplankton play a prime role in the control of marine pelagic ecosystems. While turbulence (and its associated changes in light and nutrient availability) is a determinant factor to primary production (Margalef 1974, Legendre 1981) and the selection of phytoplankton life-forms (sensu Margalef 1978), herbivorous zooplankton form one of the most important components of pelagic food webs, and exert a modulating influence upon biomass, size spectrum and specific composition of phytoplankton populations through nutrient recycling ( $\mathrm{N}$ and $\mathrm{P}$ excretion) and grazing pressure (Eppley et al. 1973, Ryther \& Sanders 1980, Conover \& Mayzaud 1984, Verity 1985, Alcaraz in press).

Turbulence and zooplankton have been generally studied independently in natural systems, mainly due to the difficulties in controlling these parameters. As a consequence, the majority of studies dealing with turbulence have been made in the laboratory, using experimental enclosures where conditions can be easily controlled, despite the problems associated with the measurement of turbulence (Perez et al. 1977, Estrada et al. 1987a) and the temporal and spatial scale constraints (Harte et al. 1980, Oviatt et al. 1980, Pilson \& Nixon 1980). The enclosure of natural plankton populations is often followed by a phytoplankton bloom and collapse (e.g. Oviatt 1981, Marrasé 1986, Estrada et al. 1987a, b, Alcaraz et al. in press). Both turbulence and herbivorous zooplankton have a quantitative influence upon phytoplankton biomass (turbulence increases the intensity of the bloom; zooplankton tends to reduce it; Alcaraz et al. in pressj. The interaction of the 2 factors, however, can have both quantitative and qualitative effects for they can also modify the events, such as a delay in the occurrence of the peak, or the development of secondary blooms (Oviatt 1981, Alcaraz et al. in press).

Data on changes in zooplankton dynamics and metabolic activity due to turbulence are scarce, and its influence on phytoplankton biomass is uncertain (Oviatt 1981, Alcaraz et al. in press). In order to understand the effects of the smaller scale turbulence the turbulent motion which acts at distances $<10^{-2} \mathrm{~m}$; Rothschild \& Osborn 1988) on the link between producers and consumers in pelagic ecosystems, a series of experiments using laboratory microcosms was performed. The goals of this paper are 2-fold: (1) to test the 
hypothesis that turbulence induces changes in the population dynamics and demographic composition of zooplankton populations; and (2) to examine the implications of these changes on the coexisting phytoplankton biomass.

\section{MATERIAL AND METHODS}

Microcosms and experimental design. The laboratory microcosms are described in detail elsewhere (Marrasé 1986, Estrada et al, 1987 a, b. Alcaraz et al. in press), and consisted of eight $30 \mathrm{l}$ perspex tubes $(200 \mathrm{~cm}$ high and $15 \mathrm{~cm}$ in diameter) placed in a temperature-controlled chamber $\left(17 \pm 1^{\circ} \mathrm{C}\right)$. Two $35 \mathrm{~W}$, $100 \mathrm{~cm}$ long fluorescent lamps (one of them GROLUX), plus a $20 \mathrm{~W}$ incandescent lamp per microcosm placed at $20 \mathrm{~cm}$ above the initial water surface, illuminated the upper half of each microcosm with a $12 \mathrm{~h}$ light/12 h dark photoperiod and provided enough heat to create a stable thermocline. Water temperature in the microcosms ranged from 24 to $17^{\circ} \mathrm{C}$ (surface and bottom). Surface temperature in the microcosms was $2 \mathrm{C}^{\circ}$ higher than that measured in the area of sampling when the experiments were run. PAR (photosynthetically available radiation) in the upper half of the microcosms was 650 to $500 \mu \mathrm{E} \mathrm{m} \mathrm{m}^{-2} \mathrm{~s}^{-1}$

Two experiments designed to test the effect of turbulence on the dynamics of herbivorous zooplankton, and the interaction of both variables on changes in phytoplankton were performed: Expt 1 (23 April to 9 May 1987 ) and Expt 2 (22 June to 3 August 1987). The experiments started at different successional stages as shown by the nutrient and chlorophyll concentrations and the composition of zooplankton populations. Expt 1 corresponded to an early successional stage with high nutrient and low chlorophyll concentrations; in Expt 2 phytoplankton was in an advanced successional stage (high chlorophyll and low nutrient concentration). There were 4 microcosms for each of 2 treatments: no turbulence with zooplankton ( $Q$ microcosms), and turbulence with zooplankton (A microcosms). Turbulence in A microcosms was generated by means of 2 circular netlon grids ( $6 \mathrm{~mm}$ and $12 \mathrm{~mm}$ mesh size) in each tube, oscillating vertically at 20 and 40 oscillations $\mathrm{min}^{-1}$ respectively, as shown in Estrada et al. (1987a, Fig. 1 centre). This system is assumed to generate the appropriate small-scale range of turbulence. Estimated vertical eddy diffusivity coefficients in such conditions were $0.5 \mathrm{~cm}^{2} \mathrm{~s}^{-1}$ for the unstirred and 1 to $5 \mathrm{~cm}^{2} \mathrm{~s}^{-1}$ for the stirred microcosms (Estrada et al. 1987a).

Coastal seawater collected from the Masnou harbour (20 km north of Barcelona) was used to fill the microcosms. Before filling the tubes, the water was thoroughly mixed and filtered through a $150 \mu \mathrm{m}$ nylon netting to exclude the larger fraction of zooplankton. In Expt 2, to estimate the initial number of copepod eggs and naupliae not retained by the $150 \mu \mathrm{m}$ netting, and so introduced initially in the tubes, 301 of the same water as used to fill the microcosms was filtered through a $60 \mu \mathrm{m}$ nylon netting and the different developmental stages of copepods counted. Zooplankton was collected simultaneously in the same waters by means of short (2 min) horizontal tows made with a $30 \mathrm{~cm}$ wide-mouth plankton net fitted with $250 \mu \mathrm{m}$ mesh nylon netting. Zooplankton samples were diluted in seawater and transported to the laboratory in 101 plastic carboys. Organisms which were damaged or showed abnormal swimming behaviour were discarded. The sample was split into aliquots and added to the microcosms at a concentration about 3 times that observed in the field. Two aliquots were saved for identification and counting. Initial chlorophyll, nutrient and zooplankton concentrations in the microcosms for both experiments are given in Tables 1 and 2 .

Expt 1 was designed to follow the short trend changes of populations, and zooplankton was allowed to reproduce throughout the experiment; whereas due to the long duration of Expt 2, adult organisms (mainly Acartia italica; Table 2) were removed $6 \mathrm{~d}$ after starting the experiment to avoid overlapping of generations. This was done by vertically screening the enclosures with $250 \mu \mathrm{m}$ mesh nylon netting adjusted to the inner wall of the microcosms and placed in the bottom of the microcosms prior to filling them.

Sampling strategy and studied variables. The specific and demographic composition of zooplankton (eggs, naupliar and copepodite stages, adults and proportion of sexes), and mean size of each developmental stage, were followed at $4 \mathrm{~d}$ intervals (Expt 1 ) and 8 to $13 \mathrm{~d}$ intervals (Expt 2) by filtering the contents of one stirred and one unstirred microcosm through $60 \mu \mathrm{m}$ nylon netting. Biomass was estimated from the mean dry weight of each developmental stage, interpolated from the length-dry weight relation found for Acartia clausi (Durbin \& Durbin 1976) and from egg dry weight estimates by Kiørboe et al. (1985). This procedure allowed sampling and examination of developmental stages, from eggs to adults, in 4 intermediate periods of the experiments, at the cost of sacrificing the microcosms sampled. The quotient number of eggs/number of females was adopted as a crude measure of fecundity, and the trophic efficiency (capacity of zooplankton to remove primary producers) was estimated through the ratio zooplankton C/phytoplankton C. Data for zooplankton dry weight/organic carbon and chlorophyll a/organic carbon relations were obtained from Hardstedt-Romeo (1982) and Banse (1977) respectively. Although the frequency of zooplankton samplings and the limited number of observations preclude an accu- 
Table 1. Mean initial values of nutrients $\left(\mu \mathrm{g}-\mathrm{at} \mathrm{l}^{-1}\right)$ and chlorophyll $\left(\mu \mathrm{g} \mathrm{l}^{-1}\right)$ concentrations in Expts 1 and 2. Q: unstirred; A: stirred. In parentheses: standard error of the mean

\begin{tabular}{|c|c|c|c|c|c|c|c|}
\hline \multicolumn{2}{|c|}{ Experiment } & $\mathrm{NO}_{3}-\mathrm{N}$ & $\mathrm{NO}_{2}-\mathrm{N}$ & $\mathrm{NH}_{4}-\mathrm{N}$ & $\mathrm{SiO}_{4}-\mathrm{Si}$ & $\mathrm{PO}_{4}-\mathrm{P}$ & chl a \\
\hline \multirow[t]{2}{*}{ Expt 1} & $Q$ & $\begin{array}{c}4.46 \\
(0.13)\end{array}$ & $\begin{array}{c}0.26 \\
(0.07)\end{array}$ & $\begin{array}{c}2.55 \\
(0.27)\end{array}$ & $\begin{array}{l}1.66 \\
(0.05)\end{array}$ & $\begin{array}{c}0.80 \\
(0.08)\end{array}$ & $\begin{array}{c}4.45 \\
(0.13)\end{array}$ \\
\hline & A & $\begin{array}{c}4.34 \\
(0.04)\end{array}$ & $\begin{array}{l}0.19 \\
(0.006)\end{array}$ & $\begin{array}{c}2.16 \\
(0.09)\end{array}$ & $\begin{array}{c}1.68 \\
(0.03)\end{array}$ & $\begin{array}{c}0.93 \\
(0.04)\end{array}$ & $\begin{array}{c}4.68 \\
(0.09)\end{array}$ \\
\hline \multirow[t]{2}{*}{ Expt 2} & $Q$ & $\begin{array}{c}0.39 \\
(0.08)\end{array}$ & $\begin{array}{c}0.50 \\
(0.009)\end{array}$ & $\begin{array}{c}0.24 \\
(0.03)\end{array}$ & $\begin{array}{c}1.52 \\
(0.11)\end{array}$ & $\begin{array}{c}0.54 \\
(0.03)\end{array}$ & $\begin{array}{l}19.80 \\
(0.87)\end{array}$ \\
\hline & A & $\begin{array}{c}0.33 \\
(0.11)\end{array}$ & $\begin{array}{c}0.50 \\
(0.006)\end{array}$ & $\begin{array}{c}0.24 \\
(0.06)\end{array}$ & $\begin{array}{c}1.53 \\
(0.02)\end{array}$ & $\begin{array}{c}0.48 \\
(0.04)\end{array}$ & $\begin{array}{l}20.44 \\
(0.53)\end{array}$ \\
\hline
\end{tabular}

Table 2. Mean composition of zooplankton added to microcosms in Expts 1 and 2

\begin{tabular}{|lcrc|}
\hline Species & Stage & Expt 1 & Expt 2 \\
\hline Acartia italica & 9 & 211 & 56 \\
Acartia italica & O & 64 & 12 \\
Acartia italica & C V-VI & - & 60 \\
Acartia italica & C IV & - & 1 \\
Acartia italica & C III & - & 1 \\
Acartia italica & C I-II & - & - \\
Acartia italica & N V-VI & - & - \\
Acartia italica & N IV & - & 6 \\
Acartia italica & N III & - & 8 \\
Acartia italica & N I-II & - & 20 \\
Acartia italica & Eggs & - & 479 \\
A. margalefi & Q & 5 & - \\
Other (Cirripede nau- & & & \\
pliae, copepodites, etc) & & 18 & 14 \\
& & & \\
\end{tabular}

Table 3. Methods used in the different measurements

\begin{tabular}{|ll|}
\hline Variable & \multicolumn{1}{c|}{ Technique } \\
Temperature & $\begin{array}{l}\text { Crison temperature probe } \\
\left( \pm 0.1 \mathrm{C}^{\circ}\right)\end{array}$ \\
Li-Cor spherical quantum sensor & $\begin{array}{l}\text { Technicon autoanalyzer } \\
\text { (Strickland \& Parsons 1972) }\end{array}$ \\
Chlorophyll & $\begin{array}{l}\text { Fluorescence } \\
\text { (Yentsch \& Menzel 1963) }\end{array}$ \\
Zooplankton & Microscope counts \\
Composition & Microscope measurements of \\
Zooplankton biomass & metasome length and conversion \\
& to dry weight (Durbin \& Durbin \\
& 1978, Kiorboe et al. 1985) \\
\hline
\end{tabular}

rate study of population dynamics or production, the method can be considered sufficient to describe the global effects of turbulence on the development of copepod populations. Nutrient and chlorophyll a concentration were sampled 50 to $55 \mathrm{~cm}$ below initial water level, $1 \mathrm{~h}$ into the light cycle. This sampling depth was adopted taking into account that in previous experiments, in which the temperature profiles were similar, and data on chlorophyll and nutrient concentration at 2 depths (above and below the thermocline, 45 and $145 \mathrm{~cm}$ depth, respectively) showed no significant differences (Estrada et al. 1987a, Alcaraz et al. in press). Samples were obtained daily in Expt 1. In Expt 2 samples were taken every day for the first $10 \mathrm{~d}$, and then less frequently (4 to $10 \mathrm{~d}$ ). Temperature and PAR profiles were taken on several occasions. The main methodological procedures are listed in Table 3.

\section{RESULTS}

\section{Chlorophyll and nutrient concentrations}

The time course of chlorophyll and nutrient concentrations followed a trend similar to that observed in previous experiments (Estrada et al. $1987 \mathrm{a}, \mathrm{b}$, Alcaraz et al. in press), with a rapid increase of chlorophyll after enclosing the water in the microcosms followed by the collapse of the bloom after nutrient depletion. There were no differences between $Q$ and $A$ tubes in the occurrence of chlorophyll peaks (Fig. 1). In Expt 1 the chlorophyll maximum occurred between the second and third day and reached significantly greater values in A tubes $\left(Q\right.$ tubes: $12.82 \pm 0.73 \mu \mathrm{g} \mathrm{l} \mathrm{l}^{-1}$; A tubes: $\left.16.8 \pm 0.38 \mu \mathrm{gl}^{-1} ; F_{\mathrm{s}}=23.41, F_{0.05(1,6)}=5.99\right)$. In Expt 2 . where the initial chlorophyll concentration was about 5 times higher (Table 1), the maximum occurred the first day and did not differ significantly between $Q$ and $A$ tubes $\left(Q\right.$ tubes: $22.86 \pm 0.38 \mu \mathrm{g} \mathrm{l}^{-1}$; A tubes: $\left.21.81 \pm 1.53 \mu \mathrm{g} \mathrm{l}^{-1} ; F_{\mathrm{s}}=0.44, F_{0.05}(1,6)=5.99\right)$, but for the $2 \mathrm{~d}$ after the bloom, the chlorophyll concentration was higher in A tubes (second day, A tubes: $16.45 \pm 0.70 \mu \mathrm{g} \mathrm{l}^{-1}$; $\mathrm{Q}$ tubes: $13.66 \pm 0.44 \mu \mathrm{g} \mathrm{l}^{-1} ; F_{\mathrm{s}}=$ $11.51, F_{0.025}(1,6)=8.81$. Third day, A tubes: $7.24 \pm 0.43 \mu \mathrm{g} \mathrm{l}^{-1} ; \mathrm{Q}$ tubes: $4.58 \pm 0.24 \mu \mathrm{g} \mathrm{l}^{-1} ; F_{\mathrm{s}}=29.0$, $\left.F_{0.01}(1,6)=13.7\right)$. In both experiments the integrated chlorophyll concentration was higher in A tubes (Expt 
1. A tubes: $64.42 \mu \mathrm{g} \mathrm{l}^{-1}$; $\mathrm{Q}$ tubes: $54.18 \mu \mathrm{g} \mathrm{l^{-1 }}$. Expt 2, A tubes: $138.41 \mu \mathrm{g} \mathrm{l}^{-1}$; $\mathrm{Q}$ tubes: $122.64 \mu \mathrm{g} \mathrm{l}^{-1}$ ).

The concentrations of $\mathrm{NO}_{3}-\mathrm{N}, \mathrm{PO}_{4}-\mathrm{P}, \mathrm{SiO}_{4}-\mathrm{Si}$ (not reported here because their trends were similar to those found in previous experiments; Alcaraz et al, in press) and $\mathrm{NH}_{4}-\mathrm{N}$ followed an opposite pattern to chlorophyll, with secondary increases due to regeneration. No significant differences were observed between $A$ and $Q$ tubes except for ammonia, whose secondary maxima were higher in A tubes (Fig. 2).

\section{Zooplankton}

Changes in the zooplankton populations have been expressed in terms of number of individuals and biomass (dry weight) for each developmental stage. The measured mean size and estimated biomass of each developmental stage, from eggs to adults, are represented in Table 4 . In both experiments the mesozooplankton populations introduced in the microcosms consisted mainly of calanoid copepods. Acartia italica was the dominant species in Masnou harbour when the experiments started (spring-summer), and the populations in the microcosms became practically monospecific. Because of their minor importance, other taxa (e.g. rotifers and tintinnids) also present in the microcosms were ignored.

Sex ratio $(\delta / q+\delta)$ appears to be modified by turbulence with a similar trend in both experiments (Table 5). In A (turbulent) tubes the proportion of males tended to decrease in comparison to $Q$ (no turbulence) tubes.

The ratio number of eggs/number of females also differed between stirred and unstirred conditions, showing in general lower values in A microcosms, at
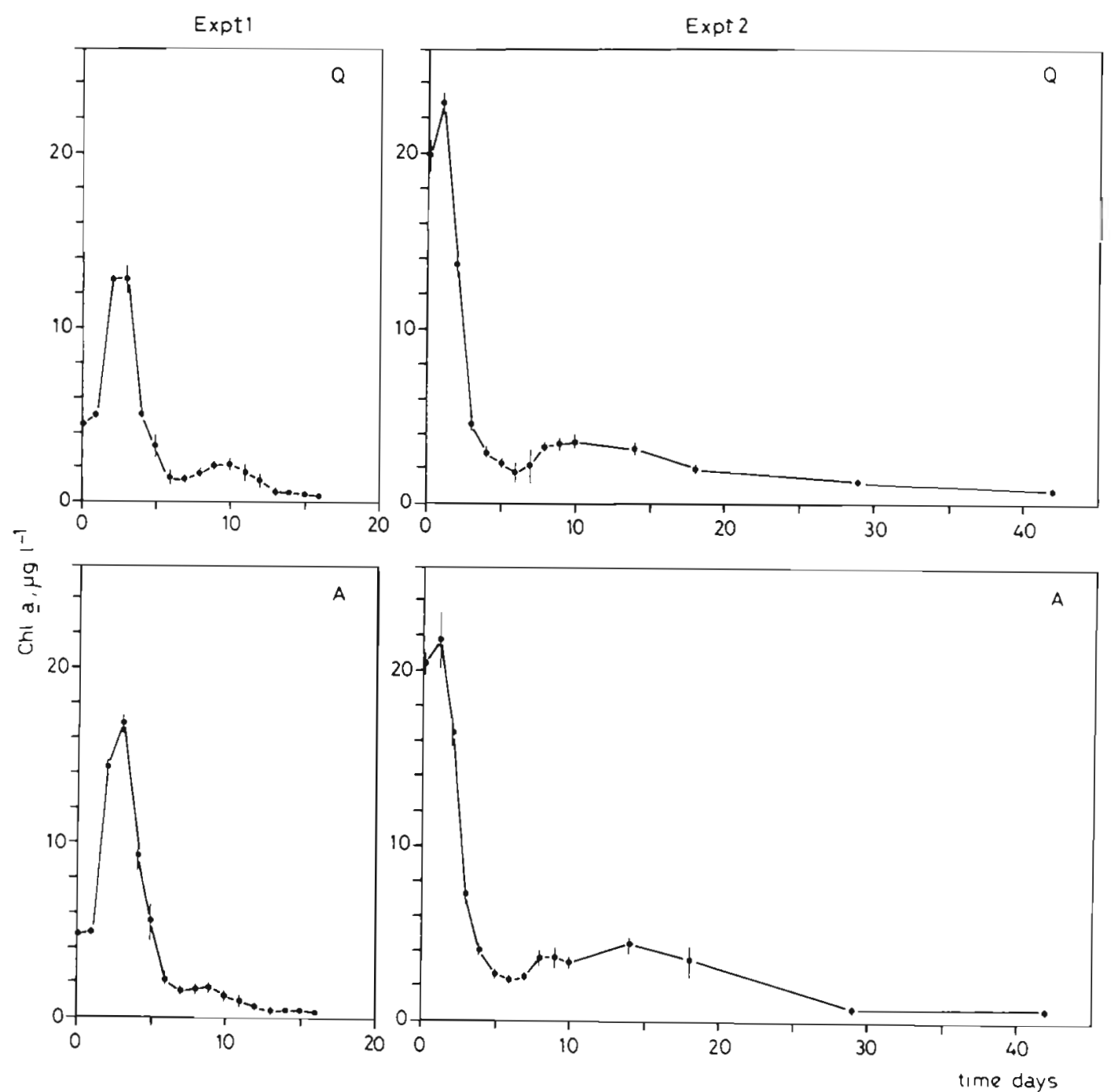

Fig. 1. Mean temporal variation of chlorophyll concentration in Expts 1 and 2. A: stirred microcosms; Q: unstirred microcosms. Vertical bars indicate standard error of the mean 


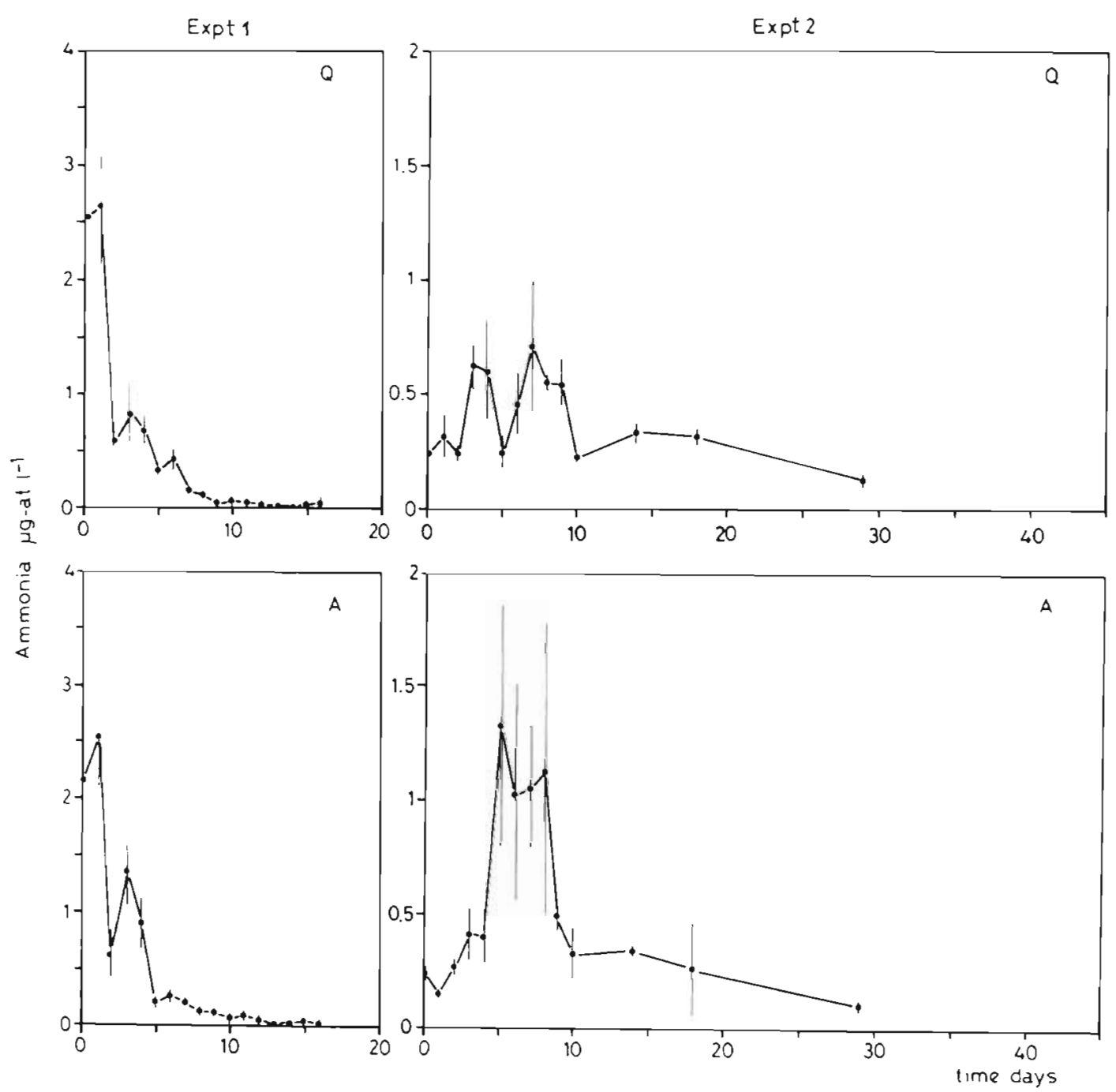

Fig. 2. Temporal variation of mean ammonia concentrations in Expts 1 and 2. A: stirred microcosms; Q: unstirred microcosms. Vertical bars indicate standard error of the mean

Table 4. Acartia italica. Mean length ( $\mathrm{mm}$ ) and biomass ( $\mathrm{ug}$ dry weight) corresponding to each developmental stage. Values calculated according the length dry weight relations given by Durbin \& Durbin (1978) for A. clausi. Dry weight of eggs from Kiørboe et al. (1985)

\begin{tabular}{|llllllllllll}
\hline & Eggs & NI-II & NIII & NIV & NV-VI & CI-II & CIII & CIV & CV-VI & o \\
\hline $\mathrm{mm}$ & 0.08 & 0.155 & 0.160 & 0.195 & 0.235 & 0.265 & 0.375 & 0.475 & 0.560 & 0.588 & 0.622 \\
$\mu \mathrm{g}$ & 0.04 & 0.04 & 0.103 & 0.181 & 0.310 & 0.430 & 0.480 & 1.000 & 1.630 & 1.900 & 2.350 \\
\hline
\end{tabular}

least for the first $2 \mathrm{wk}$ after the experiments began (Table 5).

Copepod development seems to have been accelerated in A microcosms (Fig. 3). In general, for Expt 1, the maxima of the successive stages appear earlier in $A$ tubes. In Expt 2, the adult peaks of abundance appear earlier in A tubes, but this trend was not always observed in the other developmental stages. A clearer effect seems to be the earlier end of abundance peaks in A tubes. Zooplankton biomass was always significantly lower in A tubes (Fig, 4). This effect, which was more evident in the longer lasting experiment (Expt 2), was also discussed by Oviatt (1981), although in our experiments zooplankton biomass maintained values from 7 to 16 times higher than those reported by Oviatt. On average, the values of the ratio consumers/pro- 
Table 5. Mean sex ratio $(\delta / q+\delta)$ and instantaneous values of the quotient no. eggs/no. females in Expts 1 and 2. Q: unstirred; A: stirred. In parentheses, standard error of the mean

\begin{tabular}{|c|c|c|c|c|c|}
\hline \multirow[t]{2}{*}{ Expt } & \multirow[t]{2}{*}{ Day } & \multicolumn{2}{|c|}{ Sex ratio $(\delta / 9+\delta)$} & \multicolumn{2}{|c|}{ Eggs female ${ }^{-1}$} \\
\hline & & $Q$ & $A$ & $Q$ & A \\
\hline \multirow[t]{6}{*}{1} & 0 & 0.23 & 0.23 & - & - \\
\hline & 4 & 0.29 & 0.36 & 61.6 & 89.8 \\
\hline & 8 & 0.26 & 0.17 & 111.0 & 72.6 \\
\hline & 12 & 0.40 & 0.07 & 84.8 & 50.3 \\
\hline & 16 & 0.48 & 0.19 & 119.7 & 41.4 \\
\hline & Mean & $\begin{array}{c}0.33 \\
(0.04)\end{array}$ & $\begin{array}{c}0.20 \\
(0.04)\end{array}$ & $\begin{array}{c}94.2 \\
(11.4)\end{array}$ & $\begin{array}{c}63.5 \\
(10.9)\end{array}$ \\
\hline \multirow[t]{7}{*}{2} & 0 & 0.17 & 0.17 & - & - \\
\hline & 10 & 0.39 & 0.16 & 230.5 & 108.0 \\
\hline & 18 & 0.30 & 0.11 & 6.5 & 14.5 \\
\hline & 29 & 0.52 & 0.33 & 1.2 & 2.7 \\
\hline & 42 & - & - & - & - \\
\hline & Mean & 0.34 & 0.19 & 79.4 & 41.7 \\
\hline & & $(0.07)$ & $(0.04)$ & - & - \\
\hline
\end{tabular}

Table 6. Mean ratio consumers/producers ( $\mu \mathrm{g} \mathrm{C}$ zooplankton / $\mu \mathrm{g} C$ phytoplankton) in Expts 1 and 2. In parentheses, standard error of the mean. Zooplankton dry weight/carbon relation from Hardstedt-Romeo (1982) and chlorophyll a/phytoplankton carbon relation from Banse (1977)

\begin{tabular}{|cccc|}
\hline \multirow{2}{*}{ Expt } & Day & \multicolumn{2}{c|}{ Ratio consumers/producers } \\
& & $\mathrm{Q}$ & $\mathrm{A}$ \\
\hline \multirow{2}{*}{1} & 0 & 0.031 & 0.029 \\
& 4 & 0.012 & 0.010 \\
& 8 & 0.132 & 0.095 \\
& 12 & 0.280 & 0.600 \\
& 16 & 3.210 & 1.070 \\
& Mean & 0.731 & 0.361 \\
& & $(0.619)$ & $(0.208)$ \\
& & 0.003 & 0.003 \\
& 0 & 0.091 & 0.041 \\
& 10 & 0.677 & 0.108 \\
& 18 & 0.722 & 0.081 \\
& 29 & 0.005 & 0.018 \\
& 42 & 0.300 & 0.050 \\
& Mean & $(0.164)$ & $(0.020)$ \\
& & & \\
\hline
\end{tabular}

ducers ( $\mu \mathrm{g}$ zooplankton $\mathrm{C}$ per $\mu \mathrm{g}$ phytoplankton C), were generally lower in A tubes for both experiments (Table 6), as also observed by Oviatt (1981).

\section{DISCUSSION}

In previous experiments, the interaction zooplankton-turbulence mainly affected the timing and intensity of changes in phytoplankton biomass during the first $2 \mathrm{wk}$ of the experiments (i.e. delayed phytoplankton blooms and occurrence of secondary ones in A tubes;
Alcaraz et al. in press). In the 2 experiments described here this effect was less conspicuous, probably due to the increased PAR and temperature (which induced higher rates of change in phyto- and zooplankton populations in comparison to previous experiments), as well as to differences in the initial plankton populations.

The higher integrated phytoplankton biomass achieved when turbulence and zooplankton interact was attributed by Oviatt (1981) to a reduction of zooplankton biomass (and hence grazing pressure) due to disrupting effects of turbulence on reproduction or feeding mechanisms, although a similar effect can be generated by turbulence alone (stirred tubes without zooplankton; Marrasé 1986, Estrada et al. 1987 a, b, Alcaraz et al. in press).

Even though we have no data on feeding or metabolic rates, the higher ammonia concentrations observed in A tubes suggest an increased metabolism in copepods due to turbulence. Similar metabolic trends were reported by Harris \& Malej (1986) in natural systems for Calanus helgolandicus, with higher specific excretion rates of ammonium in mixed and frontal zones in comparison to stratified ones. This supposed higher metabolism could be driven by changes in the swimming behaviour (higher frequency of escape reactions induced by turbulence; Alcaraz et al. in press). The turbulence spectrum created by the oscillating grids in our microcosms, as well as the details of the interaction between hydrodynamism and copepods, are unknown. Nevertheless it has been demonstrated that turbulence (mixing) affects the escaping capacity of copepods (Singarajah 1975), and that the hydrodynamic stimuli are perceived by the antennal sensors of copepods (Gill \& Crisp 1985). In the present case this effect could be even more important as a consequence of the higher proportion of antennal mechanoreceptors of Acartia in comparison to other calanoid copepods (Barrientos 1980, Paffenhöfer \& Stearns 1988). Higher mechanosensitivity of males, or a lower capacity to withstand metabolic stress, might be the reasons for the differences of sex ratio observed in $Q$ and $A$ microcosms. Similar reductions in the male proportion in laboratory cultures of Acartia tonsa when submitted to periodical stirring and harvesting were reported by Heinle (1970), but were attributed to the reduction on population density.

The postulated higher metabolic rates of copepods in A tubes could have also an ageing effect comparable to that reported by Shaw \& Bercaw (1962) for other crustaceans when temperature increases, thus explaining the apparent acceleration of demographic changes in $\mathrm{A}$ tubes in comparison to $\mathrm{Q}$ tubes. This was not always observed in Expt 2 probably due to the longer time lag between samplings in comparison to Expt 1. 

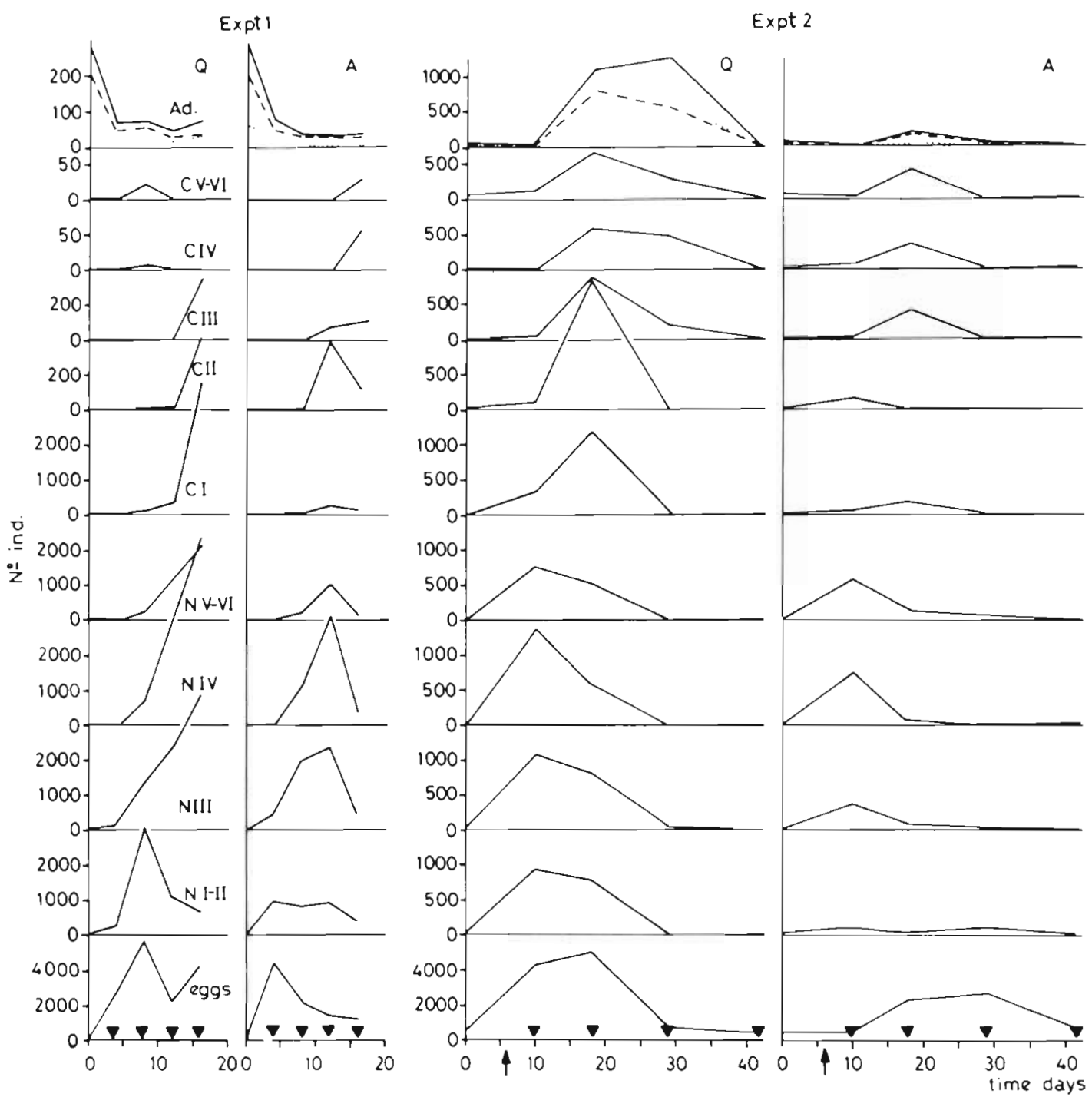

Fig. 3. Acartia italica. Mean numbers over time of the different developmental stages in Expts 1 and 2. A: stirred microcosms; Q: unstirred microcosms. In adults, (-) total number; (--) females; ( ..) males. Arrows in Expt 2 indicate when adults were removed from microcosms. Triangles indicate times of sampling

The decrease of male proportion could be the ultimate reason for the reduction of zooplankton biomass in A tubes. A significant correlation occurred between sex ratio and the quotient number of eggs/number of females in the short-term Expt $1(r=0.73, n=8)$. The lower fecundity of copepods of the genus Acartia when the proportion of males decreases has been described by Wilson \& Parrish (1971) and Alcaraz (1977), and the control exerted by sex ratio on the population density of A. italica in natural systems by Alcaraz \& Wagensberg (1978). The lack of correlation between proportion of male and eggs/female in Expt 2 might be attributable to the reduced fecundity due to food limitation (Checkley 1980 ).

Therefore, turbulence appears to have 3 major influences on marine planktonic systems: (1) enhanced phytoplankton biomass; (2) reduced consumer biomass, through changes in the demographic composition of populations (lower proportions of males and higher development rates); and (3) presumably increased metabolic activity of consumers (feeding rates and excretion rates).

The ultimate effect of turbulence would be a reduction of the trophic efficiency of the system (lower consumers biomass per unit chlorophyll or phytoplankton biomass) and accelerated turnover rates, therefore enhancing nutrient regeneration.

Acknowledgements. This research was supported by grant PR84-0061 of the CAICYT (Comision Asesora para la Investigación Cientifica y Técnical and the Institut de Ciències del Mar, CSIC. We thank Mr Barrenechea, director of the Masnou Nautical Harbour, for the facilities given to us, A. Cruz and R. 

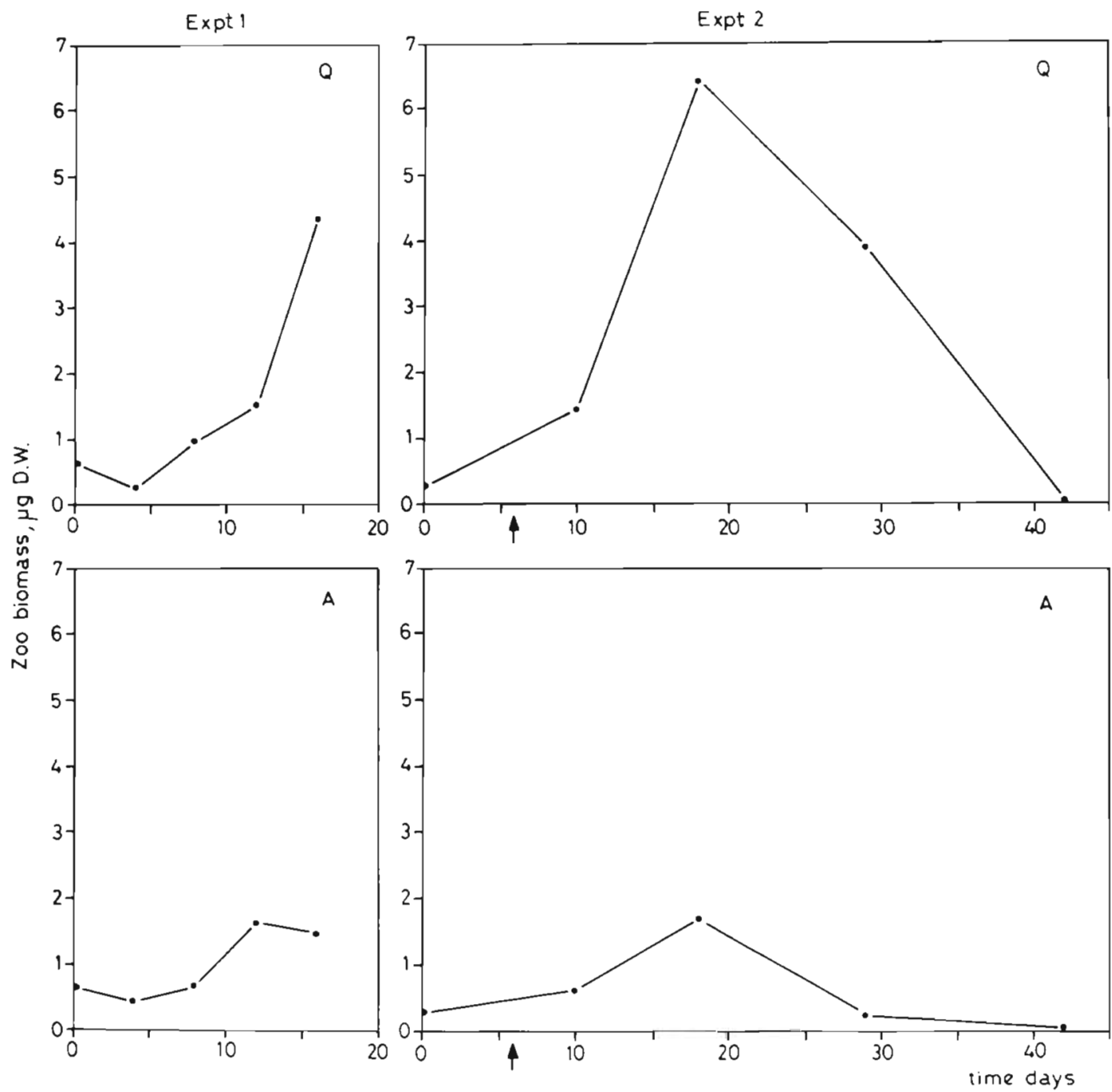

Fig. 4. Mean temporal variation of zooplankton biomass ( $\mu$ g dry wt per tube) in Expts 1 and 2. A: stirred microcosms; Q: unstirred microcosms. Arrows in Expt 2 indicate when adults were removed from microcosms

Ras, who provided technical assistance, and M. Estrada, C. Duarte, R. Margalef and the unknown referees for their critical reading of the manuscript and English corrections.

\section{LITERATURE CITED}

Alcaraz, M. (1977). Ecología, competencia y segregación en especies congenéricas de copépodos (Acartia). Ph. D. thesis, University of Barcelona

Alcaraz, M. (in press). Summer zooplankton metabolism and its relation to primary production in the Western Mediterranean. Oceanologica Acta

Alcaraz, M., Estrada, M., Marrasé, C. (in press). Interaction between turbulence and zooplankton in laboratory microcosms. Proc. of the 21st Europ. Mar. Biol. Symp., Gdansk, Poland

Alcaraz, M., Wagensberg, M. (1978). Análisis de series temporales: proporción sexual y densidad de poblaciones en copépodos. Investigación Pesq. 42: 155-165
Banse, K. (1977). Determining the carbon-to-chlorophyll ratio of natural phytoplankton. Mar. Biol. 41: 199-212

Barrientos, Y. (1980). Ultrastructure of sensory units of the first antennae of calanoid copepods. M. Sc. thesis, University of Ottawa, Ontario

Checkley, D. M. Jr. (1980). The egg production of marine planktonic copepod in relation to its food supply: laboratory studies. Limnol. Oceanogr. 25: 430-446

Conover, R. J., Mayzaud, P. (1984). Utilization of phytoplankton during the spring bloom in Nova Scotia inlet. Can. J. Fish. Aquat. Sci. 41:233-244

Durbin, E. G., Durbin, A. G. (1978). Length and weight relationships of Acartia clausi from Narragansett Bay, R. I. Limnol. Oceanogr. 23; 958-969

Eppley, R. W., Renger, E. H., Venrick, E. L., Mullin, M. (1973). A study of plankton dynamics in the central gyre of the North Pacific Ocean. Limnol. Oceanogr. 18: 534-551

Estrada, M., Alcaraz, M., Marrasé, C. (1987a). Effects of turbulence on the composition of phytoplankton assemblages in marine microcosms. Mar. Ecol. Prog. Ser. 38: 267-281

Estrada, M. Alcaraz, M., Marrasé, C. (1987b). Effect of 
reversed light gradients on the phytoplankton composition in marine microcosms. Investigación Pesq. 51: 443-458

Gill, C. W., Crisp, D. J. (1985). Sensitivity of intact and antennule amputated copepods to water disturbance. Mar. Ecol. Prog. Ser. 21: 221-227

Hardstedt-Romeo, M. (1982). Some aspects of the chemical composition of plankton from the North-Western Mediterranean sea. Mar. Biol. 70: 229-236

Harris, R. P., Malej, A. (1986). Diel patterns of ammonium excretion and grazing rhythms in Calanus helgolandicus in surface stratified waters. Mar. Ecol. Prog. Ser. 31: 75-85

Harte, J., Levy, D., Rees, J., Saegebath, E. (1980). Making microcosms an effective assessment tool. In: Giesy J. P. (ed.) Microcosms in ecological research. Technical Information Center, US Dept. of Energy, Springfield, Virginia, p. $105-137$

Heinle, D. R. (1970). Population dynamics of exploited cultures of calanoid copepods. Helgoländer wiss. Meeresunters. 20: 360-372

Kiørboe, T., Mohlenberg, F., Hamburger, K. (1985). Bioenergetics of the planktonic copepod Acartia tonsa. The relationship between feeding, egg production and respiration. Mar. Ecol. Prog. Ser. 26: 85-97

Legendre, L. (1981). Hydrodynamic control of marine phytoplankton production: the paradox of stability. In: Nihoul, J. C. J. (ed.) Ecohydrodynamics. Elsevier Oceanography Series 32: 191-207

Margalef, R. (1974). Ecologia. Omega, Barcelona

Margalef, R. (1978). Life-forms of phytoplankton as survival alternatives in an unstable environment. Oceanologica Acta 1: 493-509

Marrasé, C. (1986). Experimentos multifactoriales con plancton marino en microcosmos. Ph. D. thesis, University of Barcelona

Oviatt, C. A. (1981). Effects of different mixing schedules on phytoplankton, zooplankton and nutrients in marine microcosms. Mar. Ecol. Prog. Ser. 4: 57-67
Oviatt, C. A., Walker, H., Pilson, M. E. Q. (1980). An exploratory analysis of microcosms and ecosystem behaviour using multivariate techniques. Mar. Ecol. Prog. Ser. 2: 179-191

Paffenhofer, G. A., Stearns, D. E. (1988). Why is Acartia tonsa (Copepoda: Calanoida) restricted to nearshore environments? Mar. Ecol. Prog. Ser. 42: 33-38

Perez, K. T., Morrison, G. M., Lackie, N. F., Oviatt, C. A., Nixon, S. W., Buckley, B. A., Heltshe, J. F. (1977). The importance of physical and biotic scaling to the experimental simulation of a coastal marine ecosystem. Helgoländer wiss. Meeresunters. 30: 144-162

Pilson, M. E. Q., Nixon, S. W. (1980). Marine microcosms in ecological research. Technical Information Center, US Dept of Energy, Springfield, Virginia, p. 724-741

Rothschild, B. J., Osborn, T R. (1988). Small-scale turbulence and plankton contact rates. J. Plankton Res. 10: 465-474

Ryther, J. H., Sanders, J. G. (1980). Experimental evidence of zooplankton control of the species composition and size distribution of marine phytoplankton. Mar. Ecol. Prog. Ser. 3: $279-283$

Shaw, R. F., Bercaw, B. L. (1962). Temperature and lifespan in poikilotherm animals. Nature, Lond. 196: 454-457

Singarajah, K. V. (1975). Escape reactions of zooplankton: effects of light and turbulence. J. mar. biol. Ass. U. K. 55: $627-639$

Strickland, J. D. H., Parsons, T. R. (1972). A practical handbook of seawater analysis, 2nd edn. Bull. Fish. Res. Bd Can. 167: 1-310

Verity, P. G. (1985). Ammonia excretion rates of oceanic copepods and implications for estimates of primary production in the Sargasso Sea. Biol. Oceanogr. 3: 249-283

Wilson, D. F., Parrish, K. K. (1971). Remating in planktonic calanoid copepods. Mar. Biol. 9: 202-204

Yentsch, C. S., Menzel, D. W. (1963). A method for the determination of phytoplankton chlorophyll and phaeophytin by fluorescence. Deep Sea Res. 10: 221-231 